\title{
Cistolitectomia e ressecção de cisto renal por laparoscopia em uma cadela com aderências intraperitoneais: relato de caso
}

\author{
[Cystolithectomy and renal cyst resection by laparoscopic surgery in a female dog with \\ intraperitoneal adhesions: case report] \\ J. Pigatto ${ }^{1}$, J.P.S. Feranti ${ }^{2}$,V.H. Phol ${ }^{3}$, M.W. Ataíde ${ }^{4}$, M.V. Brun ${ }^{5}$ \\ ${ }^{1}$ Programa de Especialização em Clínica e Técnica Cirúrgica Veterinária \\ Faculdade de Agronomia e Medicina Veterinária - Universidade de Passo Fundo (UPF) \\ Caixa postal 611/631 - 99001-970 - Passo Fundo, RS \\ ${ }^{2}$ Residente - Faculdade de Agronomia e Medicina Veterinária - UPF - Passo Fundo, RS \\ ${ }^{3}$ Aluna de pós-graduação - UFSM - Santa Maria, RS \\ ${ }^{4}$ Aluna de pós-graduação - UFRGS - Porto Alegre, RS \\ ${ }^{5}$ Universidade Federal de Santa Maria (UFSM) - Santa Maria, RS
}

\begin{abstract}
RESUMO
No presente relato descreve-se a remoção de urólitos vesicais, bem como o tratamento de um cisto renal por cirurgia laparoscópica em um cão com aderências intraperitoneais. Para o acesso foram utilizados três portais, dois de $10 \mathrm{~mm}$ e um de $5 \mathrm{~mm}$, dispostos na linha média ventral e nas paredes abdominal direita e esquerda. Após a remoção das litíases, realizou-se sutura intracorpórea da parede vesical em duas camadas. O cisto renal direito foi drenado e sua cápsula extirpada. Ocorreu a perda temporária de um urólito na cavidade abdominal e sua posterior recuperação pela cirurgia laparoscópica. O paciente não apresentou recidiva da doença pelo período mínimo de 14 meses. A cirurgia laparoscópica mostrou-se eficaz na terapêutica de ambas as patologias, sem a necessidade de alteração do posicionamento dos portais.
\end{abstract}

Palavras-chave: cão, laparoscopia, urolitíase, nefropatia cística

\section{ABSTRACT}

This study reports the laparoscopic treatment of urolithys and renal cist in a dog with adherences after laparotomy. Three portals (two with $10 \mathrm{~mm}$ and one with $5 \mathrm{~mm}$ ) were used in the middle ventral line or lateral flanks. The calculi were removed, and two intracorporeal sutures were made in the vesicle tissue. The right cystic tissue was drained and its capsule was extirpated. One calculus was lost in the peritoneal cavity, but later recovered by laparoscopy. The patient did not show urinary vesicle disease during at least 14 months. The laparoscopic cistotomy appears to be adequate to remove urolithys and to treat renal cystic disease in dogs.

Keywords: dog, laparoscopy, urolithys, renal cystic disease

\section{INTRODUÇÃO}

A cistolitectomia, ou seja, a cistotomia para remoção de urólitos vesicais é o procedimento cirúrgico mais comumente realizado na bexiga em animais de companhia (Fossun et al., 2005).

A maioria dos urólitos em cães são encontrados na bexiga ou na uretra e, somente 5 a $10 \%$ estão localizados nos rins e ureteres (Nelson e Couto,
2001). A presença destes no trato urinário pode levar ao aparecimento de hematúria, cistite, incontinência, retenção urinária, complicações infecciosas e renais (Lulich et al., 2004).

A remoção cirúrgica de cistourólitos está indicada no caso de obstrução do trato urinário, em casos de cálculos grandes que não podem ser expelidos por urohidropropulsão ou após falha na dissolução medicamentosa (Smeak, 2003).

Recebido em 6 de junho de 2011 
As técnicas tradicionais para o acesso à bexiga incluem a cistotomia por laparotomia ou por laparoscopia. Rawlings et al. (2003) utilizaram a cistoscopia percutânea vídeo-assistida na remoção de pequenos urólitos vesicais em cães. Posteriormente, Brun et al. (2008) relataram com êxito três casos de cistotomia seguida de cistorrafia intracorpórea no manejo de urólitos em pequenos animais. Em eqüinos, estudos têm utilizado o acesso laparoscópico associado à minilaparotomia, bem como a litofragmentação transuretral através do laser de holmium no tratamento de cistourólitos (Judy e Galuppo, 2002; Beard, 2004; Röcken et al., 2006).

Os cistos renais são achados incomuns em cães e correspondem a cavidades revestidas por epitélio que contém fluido. Uma doença cística pode se desenvolver em animais com qualquer tipo de nefropatia crônica (Smeak, 2003).

O pseudocisto perirrenal é uma situação não associada aos canídeos e considerada rara em felinos, mas está descrita como uma entidade diferenciável dos rins policísticos. São acúmulos de fluido entre o rim e a sua cápsula, não havendo proteção por camada de epitélio (Luis et al., 2003). Tem-se descrito uma doença renal policística congênita, comuns em gatos persas e raças aparentadas (Souza, 2003). Nesta patologia, os cistos são difusos, incontáveis e atingem ambos os rins (Gattás et al., 2007).

Dor persistente, infecção, hematúria recorrente, e compressão do sistema coletor renal ou órgãos adjacentes, são indicações para o tratamento de cistos renais simples ou no contexto de doença renal policística (Beck et al., 2000; Busato, 2001).

As opções terapêuticas consistem em aspiração do conteúdo do cisto, marsupialização percutânea, ressecção cirúrgica pelo acesso aberto e, mais recentemente, por cirurgia laparoscópica (Beck et al., 2000; Gattás et al., 2007). Outra solução apontada corresponde à ressecção parcial da cápsula com ou sem omentalização, dependendo da natureza do líquido (Hill e Odesnik, 2000; Luis et al., 2003).

Neste contexto, o presente trabalho objetivou relatar um caso incomum de urólitos vesicais e cisto renal em um canino previamente submetido a duas celiotomias e com aderências intraperitoneais, descrevendo seu adequado tratamento por cirurgia laparoscópica com três portais.

\section{CASUÍSTICA}

Uma cadela, da raça poodle, com sete anos e 9 $\mathrm{kg}$, foi atendida no Hospital Veterinário da Universidade de Passo Fundo (HV/UPF), com histórico de hematúria e disúria transitória havia seis meses. Segundo relato da proprietária, o animal já havia sido submetido à antibioticoterapia e havia sido castrada a cerca de 14 meses para tratamento de piometra. Naquela ocasião apresentou deiscência dos pontos seguida de evisceração, tendo sido submetida à nova celiorrafia.

No exame clínico foi evidenciado indícios de sangue na vulva. À palpação, foram constatadas pequenas massas sólidas na região vesical e moderada algia abdominal ventral. A radiografia simples do abdômen revelou presença de cinco cálculos vesicais radiopacos, de formato piramidal, homogêneos, com bordas definidas e halo central. A ultra-sonografia demonstrou ainda o espessamento da parede vesical e uma imagem compatível com um cisto junto ao pólo cranial do rim direito (presença de estrutura arredondada de parede ecogênica lisa e regular, e com conteúdo anecogênico, estendendo-se desde a região medular e medindo $3,46 \times 2,95 \mathrm{~cm}$ ). Ambos os rins apresentaram relação córticomedular alterada (cortical adelgaçada), com limite hiperecogênico, demostrando imagem compatível com nefropatia.

A urinálise por cistocentese demonstrou: DEU 1024; $\mathrm{pH}$ 7,5; hematúria $(+++)$; proteinúria $(+++)$; bilirrubinúria $(++)$; glicosúria $(+)$; leucocitúria; presença de células vesicais (2/campo) e de cristais de fosfato triplo (2/campo). Na urocultura não houve crescimento bacteriano. O resultado do hemograma e perfil bioquímico (uréia, creatinina, ALT, FA e glicose) encontrava-se dentro dos valores de referência para a espécie.

Considerando as dimensões dos cálculos (aproximadamente 1,5cm de diâmetro), o achado ultra-sonográfico do cisto renal e a preferência da proprietária por evitar nova celiotomia, optouse pela cirurgia laparoscópica. Três dias antes da cirurgia o animal recebeu por via oral a 
associação de ampicilina sódica (22mg.kg $\left.{ }^{-1} / \mathrm{TID}\right)$ e enrofloxacina (5mg.kg $\left.{ }^{-1} / \mathrm{BID}\right)$.

O protocolo anestésico consistiu em maleato de acetilpromazina $\left(0,05 \mathrm{mg} \cdot \mathrm{kg}^{-1} / \mathrm{IM}\right)$ e sulfato de morfina $\left(0,3 \mathrm{mg} \cdot \mathrm{kg}^{-1} / \mathrm{IM}\right)$. Após 15 minutos, o animal foi induzido com diazepam $\left(0,5 \mathrm{mg} \cdot \mathrm{kg}^{-}\right.$ $\left.{ }^{1} / \mathrm{IV}\right)$ e propofol $\left(2,5 \mathrm{mg} \cdot \mathrm{kg}^{-1} / \mathrm{IV}\right)$. A manutenção foi obtida com isofluorano vaporizado em oxigênio a $100 \%$, em circuito semi-fechado. Depois de procedida a anestesia epidural com lidocaína a $2 \%$ sem vasoconstritor $(1 \mathrm{~mL} / 5 \mathrm{~kg})$ e administrado cefalotina sódica (30mg. $\left.\mathrm{kg}^{-1} / \mathrm{IV}\right)$, a bexiga foi irrigada com aproximadamente $300 \mathrm{~mL}$ de solução de iodo polivinil-pirolidona a $0,1 \%$, por meio de uma sonda Foley $\mathrm{n}^{\mathrm{o}} 8$, e esvaziada anteriormente ao procedimento.

Com o animal em decúbito dorsal, procedeu-se incisão de pele na linha média ventral préumbilical, de aproximadamente $1 \mathrm{~cm}$, através do qual foi introduzida uma cânula de $10 \mathrm{~mm}$ pela técnica aberta. A cavidade foi insuflada com $\mathrm{CO}_{2}$ até a pressão de $12 \mathrm{mmHg}$ sendo, em seguida, introduzidos dois trocartes adicionais nas paredes laterais direita $(10 \mathrm{~mm})$ e esquerda $(5 \mathrm{~mm})$, mantendo-se disposição triangular entre os portais.

A laparoscopia teve início com a liberação das aderências encontradas na linha média e parede abdominal lateral, utilizando para tanto tesoura de Metzenbaum e eletrocautério monopolar. Para o procedimento de cistotomia, a bexiga foi apreendida com pinça Babcock, sendo promovida incisão longitudinal mediana com tesoura em sua superfície ventral. Os cálculos foram coletados (Fig. 1) e colocados em um saco para remoção de tecidos, o qual teve sua abertura ocluída com o tracionamento do fio em sua borda. A bexiga foi lavada com solução fisiológica estéril por meio de uma cânula de irrigação e aspiração e, posteriormente foi introduzido o endoscópio rígido de $10 \mathrm{~mm}$ no seu lúmen para se verificar quanto à completa remoção dos cálculos e dos possíveis fragmentos.

A cistorrafia foi realizada com poliglactina 910 (3-0) em padrão contínuo simples, abrangendo todas as camadas, sendo aplicada uma sobresutura seromuscular em padrão Lembert contínuo com mesmo fio. A bexiga foi novamente irrigada por meio da sonda a fim de avaliar o selamento do defeito, o qual foi posteriormente omentalizado.

A laparoscopia teve seguimento com a exploração do rim direito, a partir do posicionamento do paciente em decúbito oblíquo esquerdo, mantendo-se a disposição original dos portais. Localizou-se então o cisto renal (Fig. 2), promovendo-se a drenagem percutânea de $20 \mathrm{~mL}$ do conteúdo com agulha de Veress. A cápsula cística foi removida junto à superfície renal com tesoura de Metzenbaum. Por fim, a gordura perirrenal foi posicionada no interior da cavidade cística sem a fixação com suturas.

Ao final do procedimento, o animal foi reposicionado em decúbito dorsal, o trocarte direito foi removido, a incisão prolongada em $1 \mathrm{~cm}$ de comprimento, e as bordas do saco exteriorizadas para fragmentação e remoção dos urólitos. Porém, ao manipular o saco após o reposicionamento do animal, verificou-se que o mesmo apresentava-se aberto e suspeitou-se que pudesse haver perda de urólito na cavidade. Não obtendo sucesso na localização de cálculo após exploração minuciosa da cavidade abdominal, optou-se por ocluir as suturas e aguardar a disponibilidade de execução do exame radiográfico no Setor correspondente, externo ao Bloco Cirúrgico. Ainda sob efeito dos fármacos anestésicos, pode-se verificar a presença de um urólito caudalmente ao rim esquerdo, a partir de um exame radiográfico simples. Após consentimento da proprietária, o animal foi novamente encaminhado ao bloco cirúrgico, reinduzido com isoflurano via máscara, e entubado.

Foi realizado o posicionamento da paciente em decúbito dorsal, o reposicionamento dos trocartes nas feridas pré-existentes, e a insuflação da cavidade de forma similar à descrita previamente. Nessa reintervenção, houve a oportunidade de utilizar o aparelho de Raios-X portátil. Para a localização precisa do urólito, uma tomada radiográfica foi obtida mantendo-se uma pinça Maryland laparoscópica previamente posicionada na parede lombar esquerda, caudalmente ao rim. Confirmou-se sua presença junto à goteira lombar esquerda, na altura da primeira vértebra lombar. 


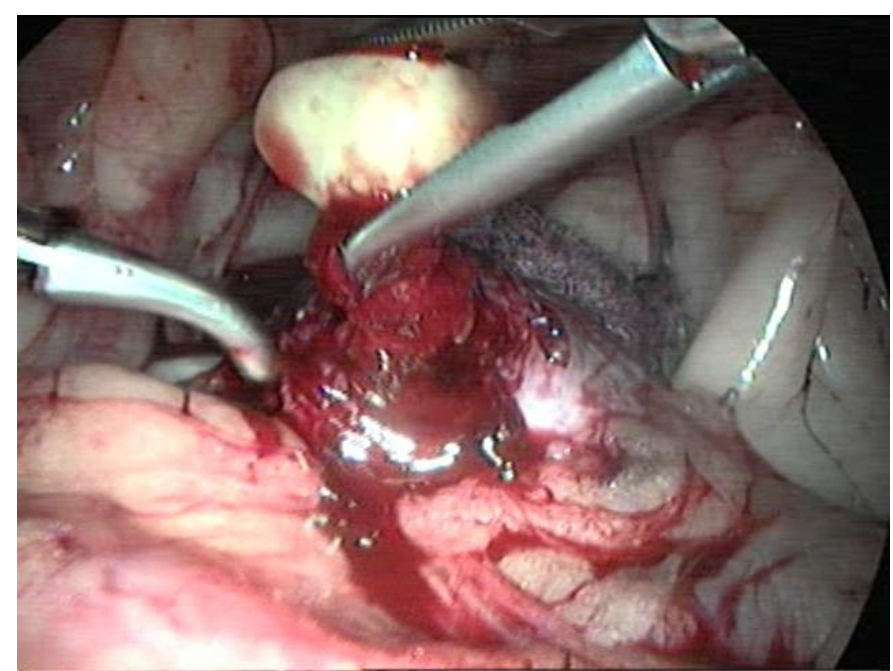

Figura 1. Remoção de um dos cálculos vesicais presentes na paciente após a cistotomia laparoscópica

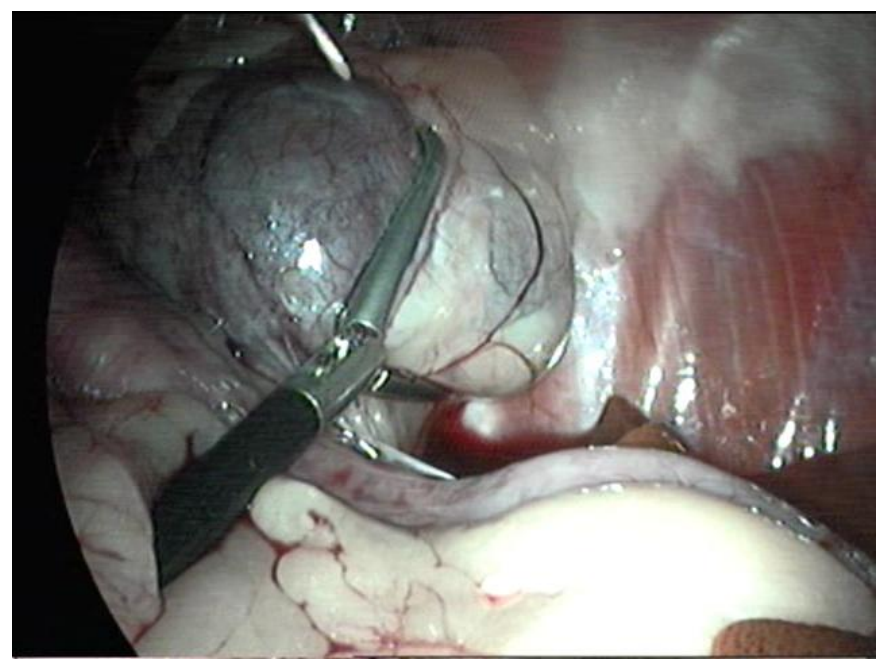

Figura 2. Visualização laparoscópica do cisto renal (entre as mandíbulas da pinça) após a cistorrafia laparoscópica.

A litíase foi então apreendida e retirada da cavidade, os trocartes removidos, e os locais de punções obliterados a nível muscular com fio de poliglactina 910 2-0, em padrão Sultan. A pele foi suturada com náilon monofilamentar 4-0 em padrão interrompido simples, totalizando 30 minutos de procedimento.

No pós-operatório, manteve-se a associação de ampicilina (22mg. $\mathrm{kg}^{-1} / \mathrm{TID} / 5$ dias) e enroflocacina (3mg. $\mathrm{kg}^{-1} / \mathrm{BID} / 10$ dias), cetoprofeno (1mg. $\mathrm{kg}^{-1} / \mathrm{SID} / 3$ dias) e morfina (0,3mg. $\mathrm{kg}^{-1} / \mathrm{QID} / 2$ dias). A sonda Foley foi removida em 48 horas, e as suturas cutâneas em sete dias.
Foi instituída dieta comercial a base de ração Urinary $^{\circledR}$ (Royal Canin) por um período de quatro meses. Contudo, por ocasião da urinálise de rotina, foram encontrados raros cristais de oxalato de cálcio três meses após o início da dieta, sendo recomendado à suspensão da ração prescrita.

Após 14 meses do procedimento cirúrgico, a cadela encontrava-se em bom estado geral, não apresentando recidiva dos sinais clínicos da doença, sendo recomendado avaliação urinária e ultrassonográfica de rotina a cada quatro meses para acompanhamento. 
A análise do conteúdo do cisto revelou: aspecto turvo; cor avermelhada; densidade 1025; $\mathrm{pH} 8,0$; presença de proteínas (+++); glicose $(+++)$; sangue oculto $(+++)$, ausência de células inflamatórias e neoplásicas. Já a análise química dos cálculos revelou presença de grande quantidade de fosfato, magnésio e amônia. Carbonato, oxalato e cálcio foram encontrados em pequena quantidade.

O tempo de procedimento cirúrgico para a cistolitectomia e ressecção do cisto renal foi de 180 minutos.

\section{DISCUSSÃO}

A urolitíase, a cistite e a incontinência urinária são as três doenças que mais acometem o trato urinário inferior dos caninos (Lulich et al., 2004). Conforme observado no presente relato, fosfato de amônio e magnésio (estruvita) constitui o tipo mais comum e, por causa de sua grande associação com infecção do trato urinário (ITU), precipitam em urina alcalina e são encontrados mais em cadelas (Smeak, 2003).

Embora a radiografia simples tenha sido adequada no diagnóstico dos cistourólitos, pelo fato de serem radiopacos e com diâmetro superior a 3mm, a ultra-sonografia foi indispensável no fornecimento das informações acerca das estruturas renais (Lulich et al., 2004). Além da constatação da presença do cisto, localizado no rim direito, foram descritas alterações ecográficas do parênquima renal como hiperecogenicidade cortical e aumento da definição do limite córtico-medular. Estas alterações tendem a associar-se com nefrite intersticial, nefroesclerose, necrose tubular e glomerulonefrites numa fase inicial (Luis et al., 2003; Beck et al., 2000).

Comparado com a técnica tradicional para o acesso a todo o trato urinário, citada por Smeak (2003) e Fossun et al. (2005), cuja incisão pode se estender desde o apêndice xifóide até o púbis, considerou-se a laparoscopia como uma técnica menos traumática, em virtude da menor lesão tecidual promovida na terapêutica cirúrgica de ambas as patologias durante único acesso.

Pacientes que já foram submetidos à intervenções cirúrgicas prévias no abdômen, como no presente caso, geralmente apresentam aderências peritoneais devido à manipulação das estruturas intracavitárias, a qual lesa a integridade do endotélio peritoneal gerando migração de fibroblastos e organização de fibrina (Gonçalves et al., 1999). Considerando a suspeita de aderências, confirmada durante o transoperatório, a utilização do método aberto para introdução do primeiro trocarte foi considerada excelente opção, não estando associada a qualquer lesão iatrogênica.

Durante a exploração da cavidade abdominal para liberação das aderências parietais e localização da bexiga, não foi adotada a posição de Trendelemburg preconizada por alguns autores como Röcken et al. (2000) e Rawlings et al. (2003), não acarretando dificuldades na realização do procedimento. Tal posição tende a facilitar a exibição da bexiga pelo deslocamento das vísceras cranialmente; porém, pode acarretar importantes disfunções cardio-respiratórias (Rudd e Hendrickson, 1998).

Os métodos estabelecidos de verificar a remoção dos urólitos (passagem da sonda através da uretra, lavagem retrógrada e inspeção do lúmen vesical) podem não ser confiáveis ou podem ser realizados inadequadamente (Lulich et al., 2004). Portanto, em conformidade com Smeak (2003) os autores indicam que se promovam radiografias trans ou pós-cirúrgica nos cães com múltiplos urólitos, para avaliar de modo mais eficiente a completa remoção destes.

Classicamente, as incisões de cistotomia devem ser ocluídas com um padrão inversor contínuo em duas camadas, com material de sutura absorvível sintético (Smeak, 2003). No presente caso, foi optado pelo padrão contínuo simples abrangendo todas as camadas como primeira linha de sutura, uma vez que possibilita boa vedação e parece diminuir o sangramento pósoperatório em cães com tendência hemorrágica (Fossun et al., 2005). Diferentemente do indicado por Rudd e Hendrickson (1998), quanto ao emprego de uma única sutura contínua simples em cistotomia laparoscópica, optou-se pela colocação de sobre-sutura seromuscular em padrão Lembert contínuo, com o intuito de minimizar o risco de extravasamento urinário e contaminação proveniente da mucosa.

A complicação associada ao procedimento cirúrgico do presente caso foi a perda temporária 
de um urólito para a cavidade abdominal, por ocasião da abertura do saco para remoção de tecidos durante a troca de decúbito do paciente. A partir dessa ocorrência, os autores passaram a indicar que, durante cistotomias laparoscópicas, seja mantida a oclusão do saco com clipe, assim que o cirurgião se certificar que todos os urólitos tenham sido retirados da bexiga. Ainda quanto a esse aspecto, a radiografia transoperatória realizada no animal em decúbito dorsal durante a segunda intervenção cirúrgica foi útil na determinação do posicionamento correto do urólito perdido, sendo indicado dispor desse recurso em caso de necessidade.

Torna-se indicado o tratamento clínico completo, por terapia dietética, diurese induzida ou antibioticoterapia apropriada para que fique minimizada a incidência de recidiva dos urólitos, a qual varia entre 12 e 25\% (Waldron, 1998). Para tanto, foi prescrita uma dieta comercial calculolítica com a finalidade de reduzir o $\mathrm{pH}$ urinário da paciente e prevenir urólitos de estruvita. A dieta continha quantidade reduzida de fósforo, magnésio, cálcio e proteína, e possuía maior quantidade de cloreto de sódio, com a finalidade de estimular a sede e induzir poliúria compensatória, resultando na produção de urina ácida. Já a restrição de proteína reduziria a produção hepática de uréia, diminuindo sua concentração na urina e contribuindo para a diurese (Nelson e Couto, 2001). A ração comercial foi prescrita por um período de quatro meses, sendo que o tempo médio necessário para dissolução dos urólitos de estruvita varia de duas semanas a sete meses (Lulich et al., 2004). Devese ressaltar que esta ração não dissolve os urólitos que não forem de estruvita e não terá eficácia se ITU persistir, ou se o animal receber outro alimento concomitante. Por esta razão, optou-se por continuar com a antibioticoterapia, mesmo com o resultado da urocultura negativo.

Segundo Lulich et al. (2004), o controle de determinados fatores de risco, em cães, que inicialmente formam urólitos de estruvita (como $\mathrm{pH}$, magnésio e fósforo reduzidos) predispõe a formação de cristais de oxalato de cálcio. Este fato foi observado, durante o exame de urina da paciente, coletado por cistocentese, três meses após instituição da terapia dietética, tendo sido recomendado sua suspensão.
Em relação ao cisto, encontrado por ocasião do exame ultrassonográfico junto ao pólo cranial do rim direito, aproveitou-se os mesmos sítios de punção da abordagem anterior, contudo com o animal posicionado em decúbito lateral esquerdo para a adequada exposição do órgão doente. Destaca-se que esta abordagem permitiu a obtenção de espaço adequado de manipulação do instrumental; porém, ao contrário do acesso pelo flanco (Gomez e Alvarenga, 2000), impossibilitou o emprego de suturas para fixação da gordura perirrenal, devido à distância e angulação dos portais em relação à região cranial do rim.

Quanto à fisiologia, os cistos renais podem originar-se do aumento da pressão dentro do rim, do aumento do gradiente das soluções salinas que banham o néfron, e das obstruções de graus variados em segmentos dos néfrons (Busato, 2001). Não existe atualmente nenhum tratamento específico para a nefropatia cística. Rins policísticos bilaterais resultam em insuficiência renal crônica. Pode-se tratar rim policístico unilateral por meio de nefrectomia, contanto que se registre uma função renal normal no rim não afetado (Smeak, 2003). Já, o tratamento do pseudocisto perirrenal consiste na drenagem e ressecção das paredes císticas (Luis et al., 2003), procedimentos executados no presente relato.

Após a localização do cisto, seu conteúdo foi aspirado percutaneamente, com auxílio de uma agulha de Veress guiada pelo endoscópio, com o intuito de minimizar a contaminação abdominal, conforme indica Apparício et al. (2006). A drenagem por punção percutânea está descrita como medida provisória ou sugerida como intervenção repetida periodicamente, para minimizar a dor e a compressão do parênquima renal (Tilley e Smith, 2003). De fato, a recidiva com nova acumulação de líquido é quase sempre uma constante, podendo acontecer dias até 12 semanas após o procedimento (Beck et al., 2000), condição não observada no presente caso.

Segundo Luis et al. (2003), é imperioso drenar o cisto e eliminar parcialmente sua cápsula, pois a não ablação é determinante na recidiva. Pode-se optar por deixar o pseudocisto aberto para a cavidade abdominal ou, sobretudo com líquido de natureza urinosa ou infectado, e pela omentalização (Beck et al., 2000). Relatos da baixa incidência de complicações e o curto 
período de hospitalização fazem da omentalização a cirurgia de escolha para o tratamento de abscessos e cistos prostáticos em cães (Apparício et al., 2006).

Diferentemente de Hill e Odesnik (2000), o qual removeu parcialmente a cápsula deixando $2 \mathrm{~cm}$ de margem para organizar a sutura contínua da cápsula ao omento, optou-se pela ressecção da cápsula cística exposta com a aproximação da gordura perirrenal do pseudocisto, sem o emprego de suturas de fixação, devido à dificuldade operacional que se apresentou com o acesso utilizado.

Embora o animal estivesse em bom estado geral, não apresentando recidiva dos sinais clínicos da doença até o período mínimo de 14 meses, é imperioso o acompanhamento ultra-sonográfico e a partir da urinálise e da bioquímica sérica renal a cada três meses (Lulich et al., 2004). Em geral, a drenagem e ressecção da parede do cisto são efetivas na eliminação dos sinais clínicos, contudo não detém a progressão da nefropatia (Beck et al., 2000).

Conclui-se portanto, que a terapêutica cirúrgica de ambas as patologias pela mesma abordagem laparoscópica é viável, e que pode contribuir significativamente para a diminuição da morbidade e mortalidade pós-operatória, quando comparada à cirurgia convencional. Reporta-se que as aderências intraperitoneais não foram empecilho na realização da cirurgia laparoscópica; contudo, ressalta-se a necessidade em utilizar o método aberto para introdução do primeiro trocarte, com o intuito de evitar lesão iatrogênica às vísceras aderidas.

\section{REFERÊNCIAS BIBLIOGRÁFICAS}

APPARÍCIO, M. VICENTE, W.R.R.; PIREZ, E.A. et al. Omentalização prostática em cães. Braz. J. Vet. Res. Anim. Sci., v.43, p.754-761, 2006.

BEARD, W. Parainguinal laparocystotomy for urolith removal in geldings. Vet. Surg., v.33, p.386-390, 2004.

BECK, J.A.; BELLENGER, C.R.; LAMB, W.A. et al. Perirenal pseudocysts in 26 cats. Aust. Vet. J., v.3, p.166-171, 2000.
BRUN, M.V.; OLIVEIRA, S.T.; MESSINA, S.A. et al. Laparoscopic cystotomy for urolith renoval in dogs: three case report. Arq. Bras. Med. Vet. Zootec., v.60, p.103-108, 2008.

BUSATO, O. Cistos renais - $A B C$ da saúde informações médicas Ltda. Copyright, 2001. Disponível em: http://www.abcdasaude.com.br/artigo.php?81. Acessado em 30/11/2009.

FOSSUN, T.W.; HEDLUND, C.S.; HULSE, A.D. et al. Cirurgia da bexiga e da uretra. In Cirurgia de pequenos animais. 2.ed. São Paulo: Roca, 2005. cap.27, p.572-609.

GATTÁS, N.; FONSECA FILHO, L.L.; CHADE, D.C. Tratamento laparoscópico de cistos renais: técnica e resultados. In: MARIANO, M.B. et al. (Ed). Videocirurgia em urologia: técnicas e resultados. São Paulo: Roca, 2007. p.127-129.

GOMEZ, H.M.; ALVARENGA, J. Nefrectomia videolaparoscópica em cães: estudo experimental. Cien. Anim. Bras., v.1, p.174. 2000.

GONÇALVES, R.M.; ESQUERDO, C.R.M.; PETROIANU, A. et al. Influência de aderências peritoneais e fio cirúrgico na tensão de ruptura da parede abdominal em ratos. Col. Bras. Cir., v.27, p.147-152, 1999.

HILL, T.P.; ODESNIK, B. J. Omentalistion of perinephric pseudocystin in cat. J. Small Anim. Pract., v.41, p.115-118, 2000.

JUDY. C.; GALUPPO, L. Endoscopic-assisted disruption of urinary calculi using a holmium: YAG laser in stading horses. Vet. Surg., v.31, p.245-250, 2002.

LUIS, J.P.S.; VIEIRA, C.; CARVALHO, A.P. et $a l$. Pseudoquisto renal subcapsular a propósito de dois casos clínicos em gato. RPCV, v.98, p.211216, 2003.

LULICH, J.P.; OSBORNE, C.A.; BARTGES, J.W. et al. Distúrbios do trato urinário inferior dos caninos. In: ETTINGER, S.J.; FELDMAN, E.C. (Ed). Tratado de medicina interna veterinária: doenças do cão e do gato. 5.ed. Rio de Janeiro: Guanabara, 2004. v.2, cap.176, p.1841-1877. 
NELSON, R.W.; COUTO, C.G. Distúrbios do trato urinário. In: _. Medicina interna de pequenos animais. 2.ed. Rio de Janeiro: Guanabara, 2001. p.453-533.

RAWLINGS, C.A. MAHAFFEY, M.B.; BARSANTI, J.A. et al. Use of laparoscopicassisted cystoscopy for removal of urinary calculi in dogs. J. Am. Vet. Med. Assoc., v.222, p.759-761, 2003.

RÖCKEN, M., SETHLE, C.; MOSEL, G. et al. Laparoscopic-assisted cystotomy for urolith removal in geldings. Vet. Surg., v.35, p.394-397, 2006.

RUDD, R.E.; HENDRICKSON, D.A. Minimally invasive surgery of the urinary system. In: FREEMAN, L.J. (Ed). Veterinary endosurgery. St. Louis: CV Mosby, 1998. p.226-236.
SMEAK, D. Distúrbios do sistema urogenital. In: BICHARD, S.J.; SHERDING, R.G. (Ed). Manual Saunders: clínica de pequenos animais. 2.ed. São Paulo: Roca, 2003, p.1001-1057.

SOUZA, H.J.M. Doença renal policística dominante. In: Coletâneas em medicina e cirurgia felina. Rio de Janeiro: L.F. Livros, 2003. p.165-172.

TILLEY, L.P.; SMITH, F.W.K. Rins policísticos. In_. Consulta veterinária em 5 minutos - espécies canina e felina. 2.ed. São Paulo: Manole, 2003. p.1104.

WALDRON, D.R. Bexiga. In: SLATTER, D. (Ed). Manual de cirurgia de pequenos animais. São Paulo: Manole, 1998. v.1, cap.106, p.17231735 . 